\title{
Evaluation of influential measures to control the monetary aspects of load haul dump machine-case study
}

\author{
J. BalaRaju, M Govinda Raj, S.N. Murthy Ch \\ Dept. Mining Engineering, NITK, Karnataka, India \\ Email: jakkulabalraj@gmail.com
}

\begin{abstract}
Each mining enterprise constantly searching out its each equipment must perform as anticipated. An efficient mode of accomplishment of that is to have a definite life cycle for a device thru an optimized upkeep strategy. Machine failures are the principle reasons for depreciation of production expenses in mechanized mining operations. Cost-effective values of both direct cost and indirect cost are very essential to assess the machine's lifecycle. Preservation costs against system disasters are handled as direct costs and other charges consisting of profits, wages, stores, electricity and transportation expenses are treated as indirect prices. On this present have a look at both direct and oblique prices associated with system disasters in underground mine are recognized. Cost controlling evaluations of system failures were achieved for both annual operating and capital cost by means of growing a life cycle cost (LCC) model. Further an attempt has been made to perceive the prevalence of system screw ups and viable price-effective measures are advised to govern the failure prevalence.
\end{abstract}

Keywords: Machine Failure, Acquisition Value, Operating Price, Renovation Cost, Disposal or Scrap Price, Lifestyles Cycle Cost.

\section{INTRODUCTION}

Each mining enterprise constantly looking for attaining the production degrees as it's projected. This can be well accomplished by maintaining the equipment/ machine with more efficient and effective manner. Improper maintenance of the machine and its operation will directly affects on performance and its consequent production expenses. Insufficient level of finished preservation can result into reduction of speed, unexpected failures, and decrease potential usage or maybe can call for substitution of the high priced device/system, [1]. Machine failures are happens because of scheduled or unscheduled discontinuities. However, the unexpected gadget screw ups and its consequent disturbances are dealt with as unscheduled discontinuities and those are stimulated on the overall productivity. In preferred downtime brought about those discontinuities and productiveness elements are taken into consideration for monetary evaluations, in which earnings and price parameters are inversely proportional due to decreasing downtime cost and in that manner growing manufacturing earnings [6]. While considering the finances of any mining venture, the price of manufacturing turns into an important thing in the present aggressive market situation. The value in keeping with ton of mined out ore/coal includes its manufacturing cost and working value. Manufacturing cost incorporates depreciation, interest on capital value and many others. And where as operating cost includes the price of maintenance, power and the labor cost, [2]. Because of this, it is recommended to the management to estimate value effectiveness of different design approaches of machineries by way of thinking about the capacity values of both preliminary and operational prices. Lifestyles Cycle Costing (LCC) method is one of the crucial devices for estimating the economic elements of the gadget or mine.

\section{LIFE CYCLE COST (LCC)}

LCC is used to assess/evaluation the value effectiveness elements of the alternative design techniques via obtaining coming near quantities of initial capital investment, maintenance and operational expenses and disposal cost for the specified time frame. Financial values of each direct and indirect charges of the machine/gadget are taken under consideration in LCC calculations. Notwithstanding this LCC technique may be used as a choice making device for the control to research the full expenditure on the device or mining task, [4].

Identity and evaluation of monetary components in LCC calculations are very hard because of unavailability of sufficient data and lifestyles of distinct facts for assessment, [5]. Consequently, few studies have been carried out for comprehensive assessment on machines screw ups and for obtaining the meaningful outcomes that integrate all financial aspects of economic information. 
In other words, LCC calculations are adopted for many of the manufacturing and production units/organizations. Those calculations play a big function in evaluation of price effective measures for controlling the fees related elements because of gadget screw ups. This includes price/expenditure from preliminary capital funding at the system/equipment to its give up of disposal/scrap. These calculations are also used to estimate the lifestyles of the device and to perceive the worthwhile paintings index of machine i.e., how long it's far worthwhile.

Sustainability characteristics and the upward push of the project finance model have furthermore induced LCC techniques to come back to the front. On the other hand nonetheless, troubles linked with the dearth of consistent facts on price, overall performance and uncertainty in the forecast of destiny expenditure is gift, [7]. In line with [11], lifestyles cycle price of the gadget/device can be segregated into 3 heads including:

- $\quad$ Acquisition cost
- $\quad$ Ownership cost and
- $\quad$ Disposal/ turnover/scrap cost LCC $($ Machine $)=$
$C($ Acq $)+C($ Own $)+C(S c r)$

Usually, acquisition fee consists of buy fee, installation price, and education and mastering to operator value, assist system and centers value, assurance cost, transporting, loading and unloading fee, and so on. It is about forty five-50\% of the full fee. Possession cost is extensively categorized into heads along with:

Working or operating cost

- Maintenance and repair price

$$
C(\text { Own })=C(\text { Ope })+C(\text { Main })
$$

In fashionable, working cost of a system is set $20-25 \%$ of the full lifestyles cycle price while preservation value is normally about $25-30 \%$ of the full LCC. The maintenance cost of a machine is surely divided into 3 heads which include:

- $\quad$ Preventive and scheduled maintenance cost

- $\quad$ Corrective maintenance cost and

- $\quad$ Emergency breakdown, accident and repair cost $C($ Main $)=C($ Pre $)+C($ Cor $)+C($ Eme $)$

In general, maintenance cost can be distributed the various following consisting of:

- $\quad$ Preventive maintenance exertions hour cost which is about $13-15 \%$ of overall maintenance price.

- $\quad$ Corrective maintenance hard work hour value about $70-75 \%$ of the entire upkeep cost.

- $\quad$ Spare components cost about 2-5\% of the overall maintenance cost.

- $\quad$ Consumable service material replacement, checking out, fault diagnosis, and so on.

- Value approximately $5 \%$ of the overall maintenance cost.

Improvement of system reliability and maintainability requires in all likelihood and real estimation of corrective value discern. The main goal of enhancing the availability of the machine and to reduce the variety of breakdowns and time required to keep and restore for returning again the system and system in ordinary operation. The corrective maintenance may additionally devour about $20-22 \%$ of the whole LCC of a machine. Consequently it is vital to review the preventive and scheduled upkeep frequencies and adjust to the real aspect behavior facts which may reduce the renovation price by using inflicting discount of spare components fee and spare elements substitute hard work hour value. The disposal/scrap value depends on numerous factors together with: whether or not system and system is associated with the chemical or nuclear product; whether their disposal cost is high in comparison to the conventional and civilian used machine and equipment.

Whether or not gadget and gadget is recoverable; Figure.1 shows the incorporated life cycle value wreck-up shape for a machine.

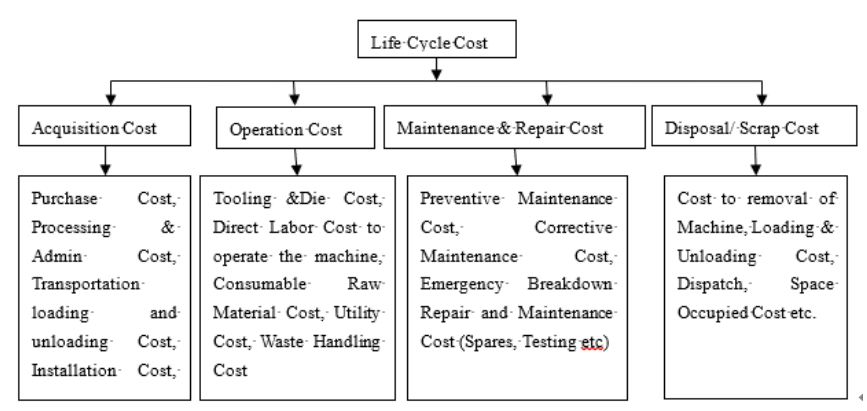

Figure 1. Integrated Life Cycle Cost (LCC) break-up structure for a machine

\section{FACTORS OF LCC}

The existence of the machine/equipment can be divided into 3 predominant stages including bodily life, earnings life and financial life. The correlation amongst those three tiers of every existence-cycle is shown with graphical representation in Figure 2. From the parent it can be located that bodily existence of the device captures some time for the brand new system to supply enough to cowl the capital fee of its procurement. It then movements into a level in which it produces larger than its protection and operational costs. An gadget completes its existence in a period where the expenses of preserving it going and the effective time misplaced to repairs it is a piece superior than what it produces throughout its period of operation. Therefore, an gadget fleet manager requires a decision making tool to perceive the severity function in which preserving the identical machine/equipment can be no longer value-powerful consequently the system can be replaced by means of either shopping a ultra-modern one or via hiring a machine with same type of specifications.

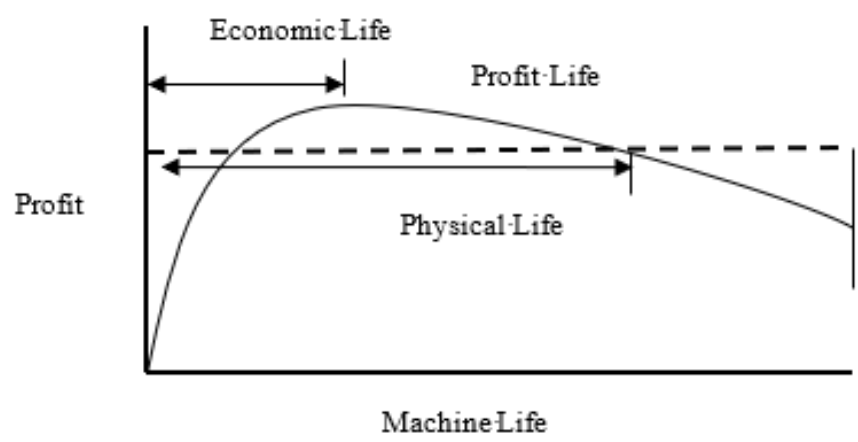

Figure 2. Graphical representation of equipment life (Source:[9]) 
The objectives of LCC are indexed bellow, [5]:

- To facilitate asset decisions to be greater efficiently envisioned;

- To become aware of the impact of all expenses rather than preliminary capital funding charges;

- To help for green company of machines/equipments for the mining projects;

- To assist choice among hard alternative.

LCC technique identifies the whole destiny costs on the gadget and earnings and If the expenses are more, it could be assessed the controlling measures to bring lower back their present fee by means of the exploit discounting techniques. So that you can accomplish above said targets the following factors of LCC were stated:

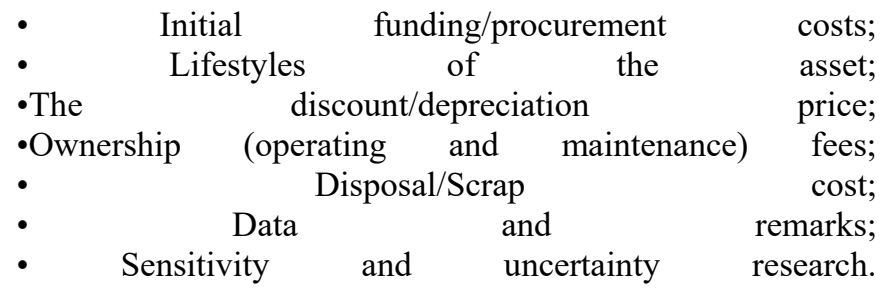

\section{REQUIRED STATISTICS FOR LCC ANALYSIS}

LCC requires particulars determined by information. Among the engineers declare that the supply of monetary information is insufficient for the analysis due to now not nicely maintained statistics. However, data is substantially available as a preliminary stage intended for LCC evaluation, [8]. Regularly records may be saved in a confined computer data but it has now not been evaluated or now not correctly applied. In trendy evaluation of any process can start with a easy calculation and expand towards more difficult statistical investigation, [7].

In order to investigate the LCC analysis in a tremendous way, there's a want for collecting the entire required records of the considered system or component. The facts can be taken in variety of modes which incorporates information received in both basically operated comparable machines/equipments and overall performance estimating info furnished by the provider or producer. It is most probable worthwhile to have a checklist of all characteristics which potentially contributes the feeeffectiveness of a particular capital asset and commercial alternate-offs can then be carry out amongst the parameters. Other resources inclusive of monetary exchange-off associations or other components of the same system might be investigated when the required records may be sufficiently no longer available, [12].

The acquaintance of reliability, utilization capacity and protection techniques are most important to discover the correlation some of the specifications of the capital price, design, purchase and disposal/scrap, and the revenue charges of operation and renovation. These notations are established in Figure 3. This gives the correlation amongst investments and its returns, the upcoming trade among charges and manufacturing functions, and the organizational techniques of an industry. Primarily based at the importance of bodily properties of an industry and cost of amassing the LCC facts, incorporated LCC database may be wrathful

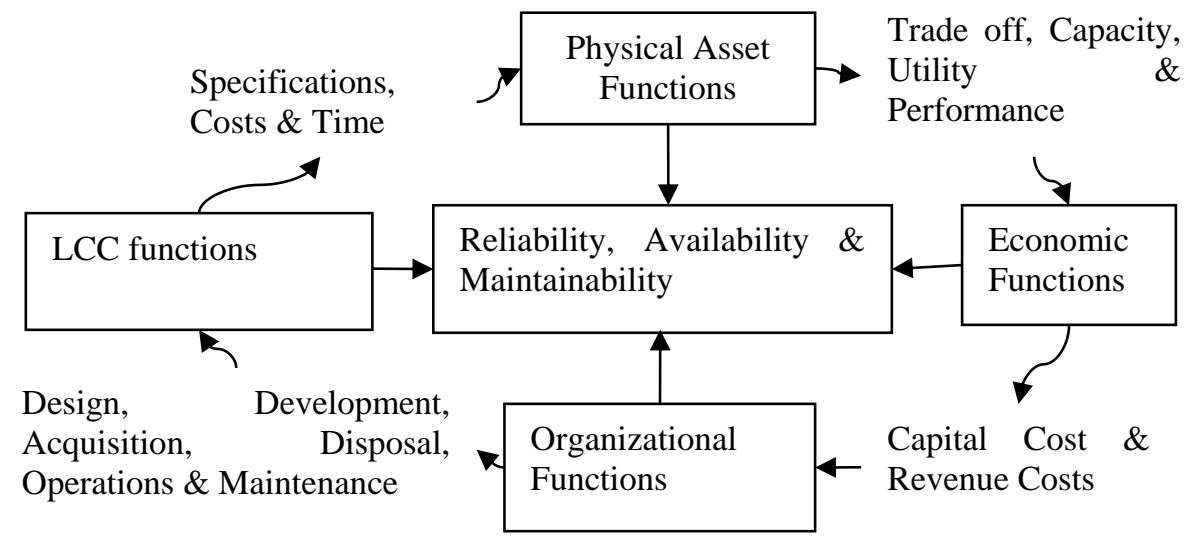

Figure.3 Key Elements in life cycle costing

First-class information system is essential for effective application of LCC technique. This device incorporates records remarks from absolutely everyone both outside and inside personnel of the industry. Dynamic commitment within the remarks system also can be a pre-needful for LCC analysis. LCC may be used as a critical and properly-prepared a part of the enterprise to take right choices on capital funding applications. Forecasting of destiny estimates won't be possible unless the life of statistics acquisition gadget and correctly analyzed LCC approach affords a brought cost to the organization/industry for selling the stepped forward management planning and control. Even supposing the to be had statistics is sufficient and precise value for the LCC analysis; nonetheless there was a hassle in projecting these metrics into the future estimates. The availability of statistical

strategies are sufficient or not to forecast the destiny cash flows associated with ownership of a fixed capital asset, is one of the predominant trouble. These essentially fall into the three classes identified of intuitive, informal and extrapolative.

\section{LCC ANALYSIS- CASE STUDY}

In order to build up sensible/experimental statistics, the prevailing case have a look at has been performed in one of the southern region of Indian mines. Whole information on monetary related elements of LHDs had been amassed for the 
evaluation. This includes each constant and variable cost of operation and renovation.

\section{Case takes a look at background}

Small scale mining industries constantly works with optimizing/minimizing the procurement techniques. The artificial/alternative in procurement is to hold the existing equipment with a green and powerful mode of operation as an alternative of buying a modern day one. Research of all of the monetary parameters of device/system is possible via adopting/applying a brand new selection-making device i.e., LCC method for numerous operations. The case in this observes considered five varieties of LHD machines with a capability of 2.5 cu.m for underground mining operations. The useful lifestyles of the system (existence span) is a widespread metric to recall because it installation the anticipated time for achieving the projected production and financial goals. The average useful existence of the LHD machines is set 20,000 hours or greater. Its miles relying upon the scheduled/preventive maintenance and powerful enterprise and implementation of advanced life improvement technology. Extraordinary additives in a machine have exclusive existence expectancies. The various components require alternative/ recovery earlier than its envisioned life span due to flawed protection and operation techniques. Once this has been incurred there follows a drop in yearly manufacturing costs of the mine in consequent years. Fall of annual production prices because of device breakdowns is investigated with the aid of analyzing the costs of the gadget over its lifetime.

Economic values of LHD machines are amassed for three subsequent financial years. These values includes all of the parameters of the machine which includes preliminary capital funding/procurement cost, expenditure of the system for the duration of its operating, price of equipment breakdowns known as maintenance value and disposal/scrap price after the protection. Five numbers of machines are considered for the prevailing analysis, each individual LHD machine unit cost inclusive of all excise charges is taken as approximately 52.78 lakhs .This metric may not be a fixed and fast price and may be numerous because of modifications marketplace scenarios. Overall working cost of the machines may be evaluated from the product of cost of manufacturing to its manufacturing quantity of the device in a unique period of time and is shown in Table 1.

Table 1. Operating costs of the LHD machines in Year Wise

\begin{tabular}{|l|l|l|l|}
\hline \multirow{2}{*}{\begin{tabular}{l} 
Description of Cost in /Year \\
\cline { 2 - 4 }
\end{tabular}} & $\mathbf{2 0 1 3 - 1 4}$ & $\mathbf{2 0 1 4 - 1 5}$ & $\mathbf{2 0 1 5 - 1 6}$ \\
\cline { 2 - 4 } & Cos/Tonne (Rs) & Cos/Tonne (Rs) & Cos/Tonne (Rs) \\
\hline Sales/Wages & $2,585.97$ & $3,081.26$ & $3,484.11$ \\
\hline Explosives & 33.31 & 31.37 & 33.88 \\
\hline Stores & 218.52 & 282.76 & 319.97 \\
\hline Power & 87.66 & 96.28 & 188.19 \\
\hline Other Expenses & 259.43 & 477.58 & 368.08 \\
\hline Coal Transport & 0 & 0 & 0 \\
\hline Sand Transport & 86.02 & 109.72 & 59.78 \\
\hline Interest & 0 & 0 & 0 \\
\hline Depreciation & 22.83 & 33.15 & 64.93 \\
\hline Cost of Production & $3,293.74$ & $4,112.11$ & $4,518.94$ \\
\hline Production Quantity & $6,22,781$ Tonnes & $5,36,661$ Tonnes & $5,63,074$ Tonnes \\
\hline Total Operating Cost & $205,12,78,691.00$ & $220,68,09,065.00$ & $254,44,97,622.00$ \\
\hline
\end{tabular}

Table 2. Maintenance cost of the lhd machines in year wise

\begin{tabular}{|c|c|c|c|}
\hline Cost Parameter in Lakhs/Year & $\mathbf{2 0 1 3 - 1 4}$ & $\mathbf{2 0 1 4 - 1 5}$ & $\mathbf{2 0 1 5 - 1 6}$ \\
\hline Cost of Breakdown Hrs-Cbh & 1,303 & 4366 & 2357 \\
\hline Cost of waiting Hrs-Cwh & 5213 & 5815 & 7248 \\
\hline Cost of Repair\& Maint.-Cr\&mh & 69 & 215 & 189 \\
\hline Cost of Spare Parts-Csp\&raw/m & 14 & 18 & 28 \\
\hline Cost of Service\& Lubrication-Csl\&t & 4 & 6 & 5 \\
\hline Total Cost of Machine Breakdown-TCm/b & $\mathbf{6 6 0 5}$ & $\mathbf{1 0 4 2 2}$ & $\mathbf{9 8 2 8}$ \\
\hline
\end{tabular}

Total value of system breakdowns called maintenance price is shown in Table 2 . This consists of all the parameters linked to upkeep cost and can be calculated from the bellow expression.

$$
T C\left(\frac{m}{b}\right)=C b h+C w h+C r \& m h+C s p \& r a w+C s, l \& g
$$


where, $\mathrm{TCm} \backslash \mathrm{b}=$ Total loss due to machine breakdowns, repair and maintenance cost

$\mathrm{Cbh}=$ Cost of idle hours due to breakdowns of machine, period calculated up to handover the breakdown machine to the maintenance department for repair and maintenance.

$\mathrm{Cwh}=$ Waiting hours equalent cost for repair and maintenance. $\mathrm{Cr} \& \mathrm{mh}=$ Repair and maintenance cost

Csp\&raw $=$ Cost of spare parts and other raw material used for specific breakdown

$\mathrm{Cs}, 1 \& \mathrm{~g}=$ Cost of service, lubrication, greasing, testing and fault diagnosis etc.,

After successful of entirety of preventive protection, corrective maintenance and emergency breakdown repair and maintenance of repaired gadget components are reassembled for reoperation of the system in to the paintings environment. The cost in the course of this era of statement can be dealt with as disposal/scrap price which incorporates packing, transportation and loading and unloading fees and are shown in Table 3.

Table 3. Disposal/scrap cost of the LHD machines in year wise

\begin{tabular}{|c|c|c|c|}
\hline $\begin{array}{c}\text { Cost Parameter in } \\
\text { Lakhs/Year }\end{array}$ & $\mathbf{2 0 3 - 1 4}$ & $\mathbf{2 0 1 4 - 1 5}$ & $\mathbf{2 0 1 5 - 1 6}$ \\
\hline Packing & $1,44,000$ & $1,86,000$ & $1,74,000$ \\
\hline Transporting & $1,89,345$ & $2,60,000$ & $2,30,260$ \\
\hline Loading \&Un loading & $2,88,000$ & $2,95,400$ & $2,90,000$ \\
\hline Disposal/Scrap Cost & $\mathbf{6 , 2 1 , 3 4 5}$ & $\mathbf{7 , 4 1 , 4 0 0}$ & $\mathbf{6 , 9 4 , 2 6 0}$ \\
\hline
\end{tabular}

Expenditure on the gadget throughout its running shows running value and costs related to breakdowns shows renovation and disposal/scrap charges with percentage distributions are proven personally in Figure 1, Figure2 and Figure3.

Life cycle cost of the LHD machines have been calculated for three corresponding financial years from the accumulated information of acquisition price, ownership cost and disposal/ scrap charges and is proven in Table 4 . The evaluation reveals that, initial capital investment/ procurement (acquisition) fee may be considered in all of the monetary years whilst calculating the whole existence cycle cost of the machine. However, in real practice procurement of system is achieved in a single time and it will be applied till the quit of its lifestyles. Expenditure at the machine during its operation can be located maximum at 254,44 lakhs inside the monetary 12 months 2015 and the corresponding least cost can be observed at 205,12 lakhs in the financial 12 months 2013 and for the monetary 12 months 2014 is medium fee among. Upkeep charges are located that very least cost approximately 66,05 lakhs in the year 2013 and most at 2014 approximately 104,22 lakhs. It can be understood that form the Table 2, a large difference can be observed in economic values between first two consequent years. This is due to prevalence of major breakdowns and the machine is idle for a longer period because of its breakdowns within the economic yr 2014 in comparison to two subsequent years. Disposal/scrap prices of the machines are accelerated from first financial 12 months to closing due to size of the components and majority of disasters. The share distribution of total life cycle cost for three corresponding years is shown in Table 4.

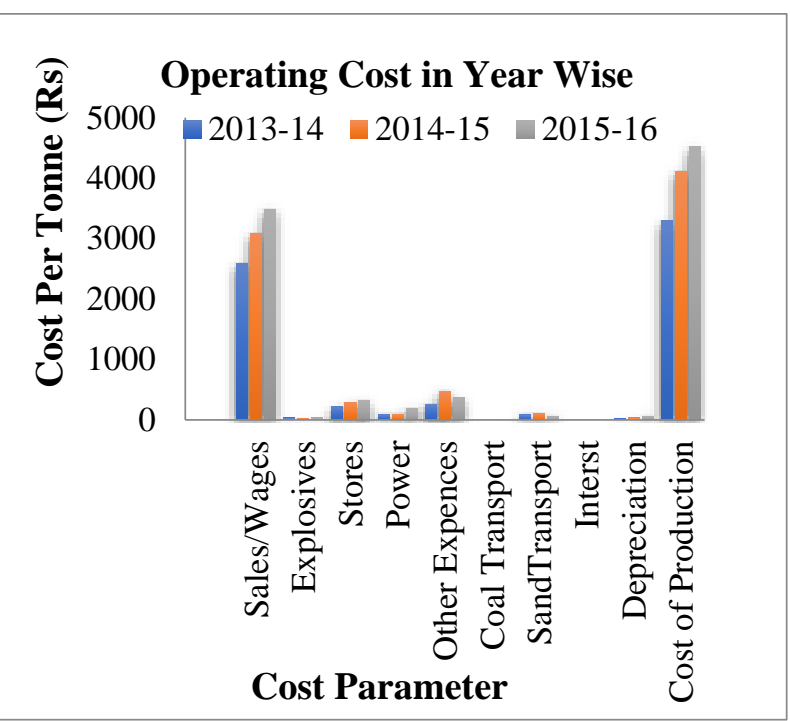

Figure 1. Operating cost in year wise

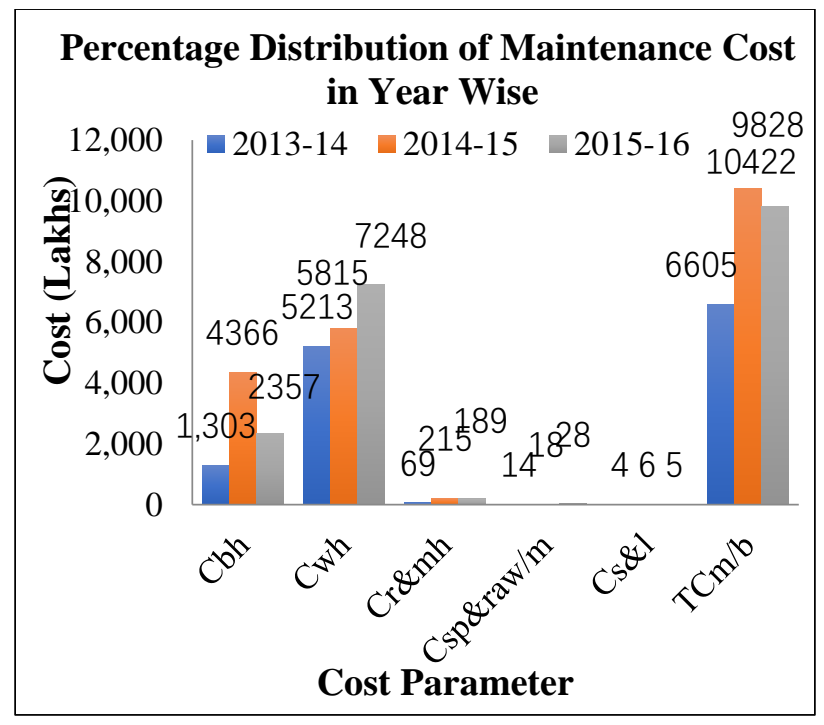

Figure 2. Maintenance cost in year wise

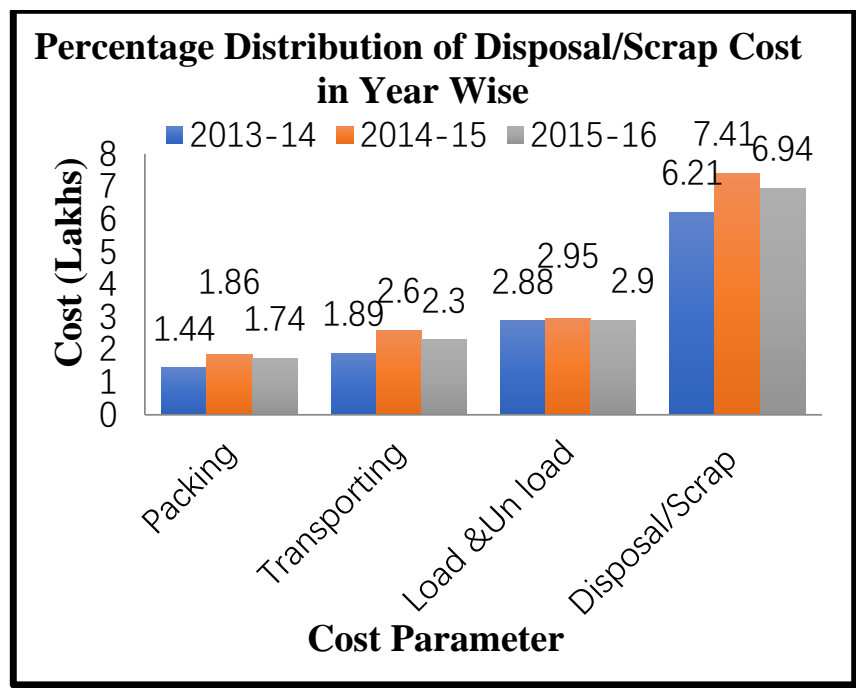

Figure 3. Disposal/scrap cost in year wise

As of the above discussion, it can be whispered that preservation price should be taken into consideration as a deliberated component used for decrease of value and has a 
good enough potential to show across the economic energy of the various industries. There may be a crucial need for evaluation of life of the device and the inter-relationship among guys and machinery when the downtime expenses are very excessive. Attempt to ebook an oblique price will carry the exact attention of device breakdowns which have an important role towards the downtime value.

Table 4. Percentage distribution of total cost in year wise

\begin{tabular}{|c|c|c|c|}
\hline \multicolumn{4}{|c|}{ Percentage Distribution of Total Cost in Year Wise } \\
\hline $\begin{array}{c}\text { Cost Parameter in Lakhs/ } \\
\text { Year }\end{array}$ & $\begin{array}{c}\mathbf{2 0 1 3 -} \\
\mathbf{1 4}\end{array}$ & $\begin{array}{c}\mathbf{2 0 1 4 -} \\
\mathbf{1 5}\end{array}$ & $\begin{array}{c}\mathbf{2 0 1 5 -} \\
\mathbf{1 6}\end{array}$ \\
\hline Acquisition Cost & 2,63 & $* * *$ & $* * *$ \\
\hline Operating Cost & 205,12 & 220,68 & 254,44 \\
\hline Maintenance Cost & 66,05 & 104,22 & 98,28 \\
\hline Disposal/ Scrap & 6 & 7 & 8 \\
\hline Life Cycle Cost & 273,88 & 327,62 & 355,45 \\
\hline
\end{tabular}

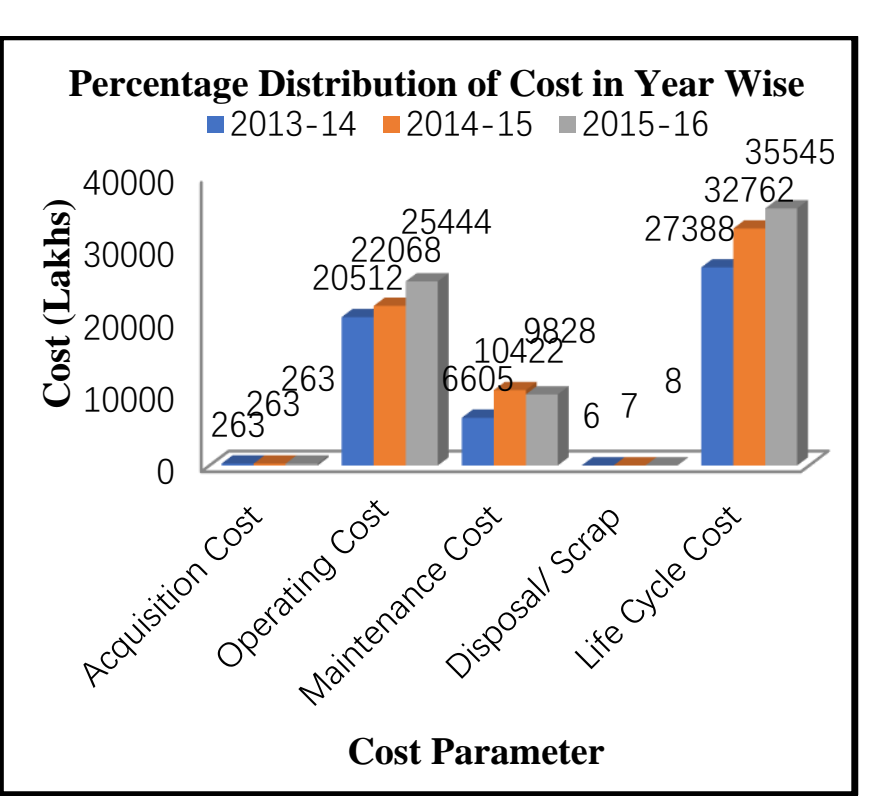

Figure 4. Percentage distribution of total life cycle costs in year wise

\section{CONCLUSION}

The industry procures machines, which form a maximum important part of the capital spending, on an ordinary basis and the selection to buy them is based on the LCC approach. Overall LCC of 5 LHD machines were calculated on the premise of gathered information for 3 consequent economic years from a coal mine in southern place of India. It can be concluded that the LCC of the machines within the financial 12 months 2015-16 is bigger than the last ones, especially due to expenditure at the machines at some point of its operation and its prices linked to down times consisting of cost of breakdown hours and cost of idle hours.

The findings from the statistics analysis are compared with respect to monetary values or metrics (Figure 4). Throughout the assessment of LCC of the LHDs, all the monetary property linked with machine/equipment are followed. From the evaluation it's far determined that LCC price of LHDs with monetary years 2013, 2014 and 2015 were located to be 273,88lacks, 327,62lakhs and 355,45lakhs respectively. Increases in LCC metrics shows that the LHDs aren't maintained and operated properly. These situations result towards direct effect on cost of manufacturing and its productiveness/charge of production of the machines. The productiveness of the LHDs can be progressed by controlling the cost of breakdown hours, price of idle hours. The value of production of LHDs may be controlled by using adopting proper preventive and corrective renovation strategies and decreasing/optimizing the expenditure on machines all through its operation. This can be viable by means of the minimizing the operator associated troubles during the operation of LHD. Additionally with using standardized fluids, lubricants, grease and every day offerings will hold the preservation expenses in lower levels for aid gadget. Right unique evaluation of utilization factor is one of the key elements for evaluating and explores new strategies for improving OEE in any type of mining equipment.

\section{REFERENCES}

[1] Alakesh M. (2016). A text book of reliability and maintainability engineering, I.K International Publishing House Pvt. Ltd.

[2] Arputharaj M.M. (2015). Effect of equipment utilization on economics of mining project-A case study, Journal Impact Factor6.3, pp. 07-13.

[3] Barringer H.P., David P.W. (1995), Where's my data for making reliability improvements, Fourth International Conference on Process Plant Reliability, Gulf Publishing Company, Houston, TX.

[4] Bloch H.P., Fred K.G. (1995). Simplified life-cycle cost computations applied in the hydrocarbon processing industries, Fourth International Conference on Process Plant Reliability, Gulf Publishing Company, Houston, TX.

[5] David G.W. (1997). Life cycle costing--theory, information acquisition and application, International Journal of Project Management, Vol. 15, No. 6, pp. 335-344.

[6] Douglas J. (1978). Equipment Costs by current methods journal of construction division ASCE 104 (C02), pp. 191-225.

[7] Flanagan R. (2005), Whole life appraisal for construction, Oxford. Blackwell Publishing.

[8] Griesshammer R., Benoit C., Dreyer L.C., Flysjö A., Manhart A., Mazjin B., Methot A.L. Weidema B. (2006). Feasibility study. integration of social aspects into LCA, Paris, UNEP/SETAC Life Cycle Initiative.

[9] Nepal M.P., Park M. (2004). Downtime model development for construction equipment management. engineering, construction and architectural management, Vol. 11, No. 3, pp. 199-210. 
[10] Selin G. (2016). The use of life cycle techniques in the assessment of sustainability, Procedia - Social and Behavioral Sciences, No. 216, pp. 916 - 922.
[11] Shakti N. (2015). Performance analysis of heavy earth moving machineries (Hemm), Opencast Coal Mines, Thesis. 